\title{
LOADS ACTING ON THE SPARE WHEEL DURING OPERATING THE TRUCK
}

\section{Mariusz STAŃCO ${ }^{1}$, Jerzy CZMOCHOWSKI ${ }^{2}$, Pawel MAŚLAK ${ }^{3}$}

1 University of Science and Technology, Faculty of Mechanical Engineering, Department of Machine Design and Research, 5 Łukasiewicza st., 50-370 Wroclaw, Poland, e-mail: mariusz.stanco@pwr.edu.pl

2 University of Science and Technology, Faculty of Mechanical Engineering, Department of Machine Design and Research, 5 Łukasiewicza st., 50-370 Wroclaw, Poland, e-mail: jerzy.czmochowski@pwr.edu.pl

3 University of Science and Technology, Faculty of Mechanical Engineering, Department of Machine Design and Research, 5 Łukasiewicza st., 50-370 Wroclaw, Poland, e-mail: pawel.maslak@pwr.edu.pl

\section{Introduction}

Loads caused by the use of vehicles, especially those that run on off-road are very often difficult to define, because each terrain is different. In many literature items are given general values of overload which should be taken while designing any vehicle. These values are average values measured for the whole vehicle [2,3]. In the literature, it is difficult to find information about the loads of a particular vehicle element. Usually, the general available values are adopted, for which the appropriate safety factor is then selected. Such a design method leads to overestimation or underestimation of the designed element. An example for which the literature does not provide any guidance is the spare wheel bracket, which in special-purpose trucks often has to be installed just behind the cabin. The center of gravity of the wheel is raised above the upper shelf of the longitudinal frame (Fig. 1). In addition to the forces resulting from the mass of the wheel itself, such an element has to transfer the loads resulting from its inertia when moving on paved roads and off-road roads.

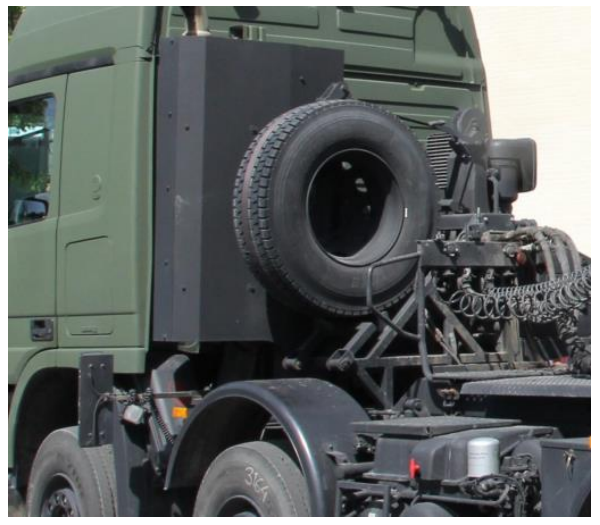

Fig. 1. Spare wheel behind the cabin [1]

The installation of a spare wheel behind the cabin is caused by the lack of free space within the frame of the longitudinal frame or the need to provide adequate ground clearance, which ensures the vehicle moves along off-roads.

\section{Experimental research}

Experimental tests of loads acting on the spare wheel installed just behind the cab were carried out. The tests consisted of measurements of inertia forces during vehicle operation in the field as well as along paved roads. In the center of gravity of the wheel there is an acceleration sensor measuring the acceleration in three directions. A piezoresistive sensor measuring also the gravity constant was used for the measurements. The sensors were connected by means of cables with a recorder placed in the vehicle's cabin. 


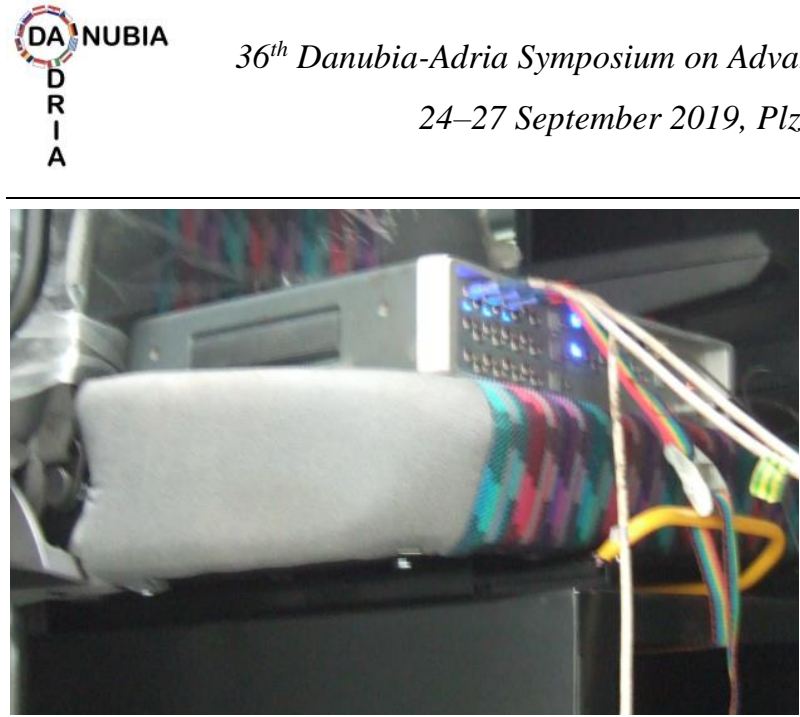

Fig. 2. Recorder inside the cabin.

\section{Measurement results}

Measurements of overloads were obtained from the measurements, which are presented in the form of diagrams shown in Fig. 3-5. The presented measurement results are shown for the maximum values for individual vehicle driving directions and the corresponding remaining directions in a given measurement time. The $\mathrm{X}$ direction is the measurement along the vehicle, the $\mathrm{Y}$ direction across the vehicle, while the $\mathrm{Z}$ direction is the vertical direction.

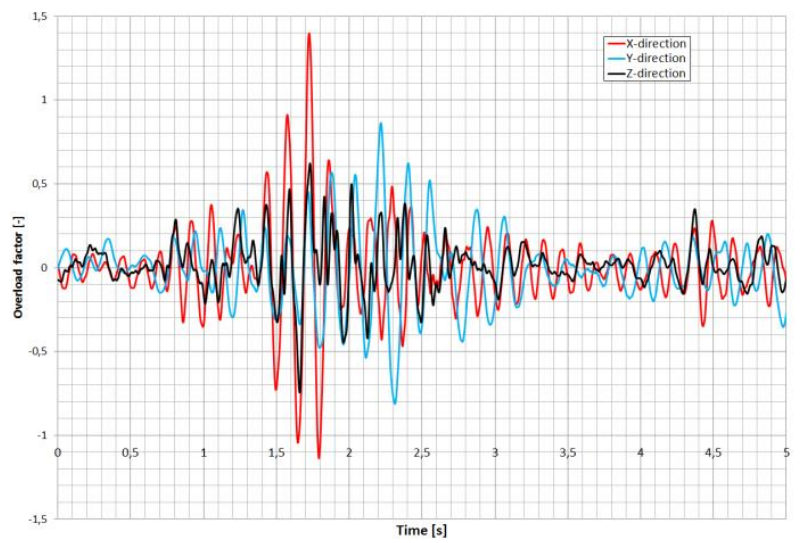

Fig. 3. Maximum longitudinal loads acting on the wheel

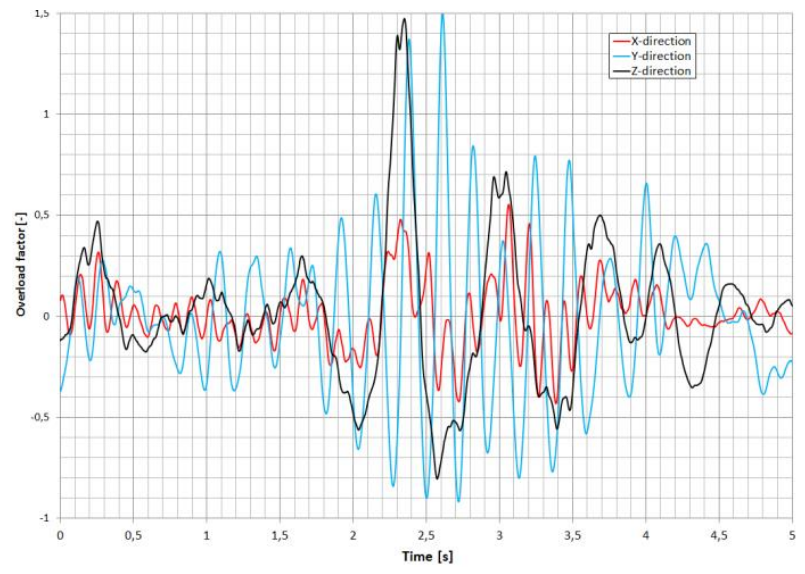

Fig. 4. Maximum transverse loads acting on the wheel

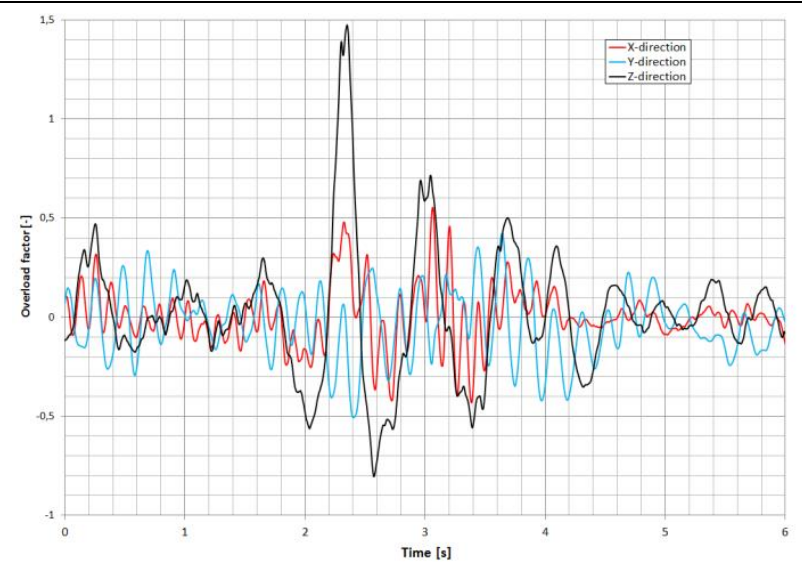

Fig. 5. Maximum vertical overloads acting on the wheel

\section{Conclusions}

The tests allowed determination of the loads acting on the spare wheel while driving in variable road conditions. Figure 6 shows the overload sequences for the maximum values in each direction. It can be seen that in each of the directions the maximum value of the overload is similar and amounts to about 1.5.

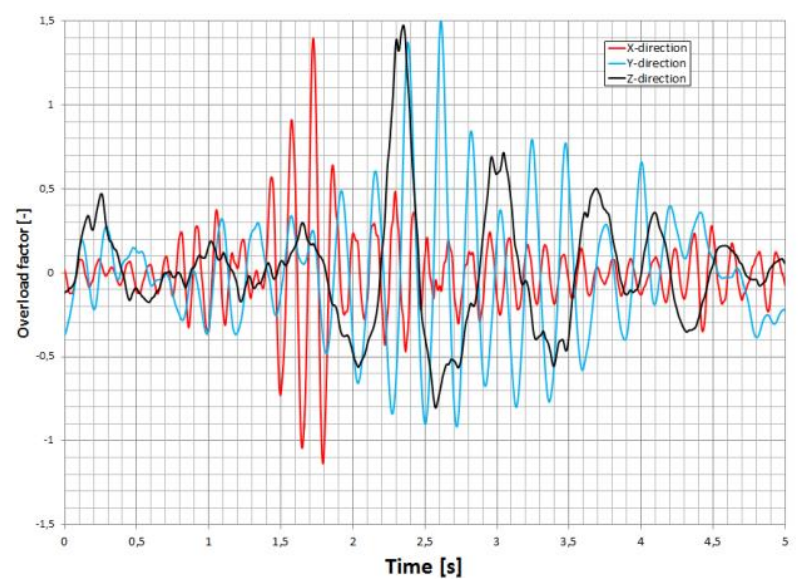

Fig. 5. Maximum longitudinal (X), transverse $(Y)$ and vertical $(\mathrm{Z})$ overloading forces acting on the spare wheel while driving.

\section{References}

[1] https://commons.wikimedia.org/wiki/File:Lippujuhl an_p\%C3\%A4iv\%C3\%A4n_paraati_2014_065_Ka rjalan_prikaati_Mercedes-Benz_Actros.JPG

[2] Stańco M., Kosobudzki M., Derlukiewicz D., The experimental identification of effort state oftruck load carrying frame. Croatian Society of Mechanics, 2013. s. 254-255

[3] Kosobudzki M., Stańco M., Kowalczyk M., Akwizycja obciążeń dynamicznych działających na pojazd generowanych przez układ jezdny. Transport Przemysłowy. 2007, nr 4, s. 82-85 